\title{
Index rerum ad Vol. 15
}

ABO blood groups and disease 268

in Australia 309

Swedish gipsies 134

- interaction with Rh groups 224 Anti-A titre and smallpox vaccination 13 Australia, distribution of blood groups 309 dermatoglyphics in aborigines 145

Beta thalassaemia, see Thalassaemia Blood group A antigen and vaccinia virus 13 distribution in Australia 309 Swedish gipsies 134

gene frequencies, estimation 345 Blood groups and diseases 261 surnames, correlation in Australia

309

- $\quad$, see also ABO, Duffy, Gc, Gm, Haptoglobins, Kell, MN, P, Secretor character and Transferrins

Blood pressure, correlation between relatives 87 Brazil, congenital malformations 177

Gc types 116

race mixture 119 Camptodactyly 70

Cholelithiasis, familial occurrence 159 Colour blindness, genetics 97 Consanguineous marriages, see Inbreeding Curved little finger, genetics 70 Cytogenetics, mutation in tissue culture 155 Delta thalassaemia, see Thalassaemia Dermatoglyphics in Australian aborigines 145

- Down syndrome, diagnostic value 3

Down syndrome, dermal configurations 3

Duchenne muscular dystrophy, see

Muscular dystrophy Duffy blood groups and disease 286 Ear lobe attachment types in India 77

Enzymes in serum, see Phosphatase and

Pseudocholinesterase Finland, distribution of Gc types 45

Tf types 63

Foetal haemoglobin, persistent, and delta

thalassaemia 190 Gc types, distribution in Brazil (Negroes

and Whites) 116

Finland 45

Lapps (Finnish) 45

(Norwegian) 126

- Northern Italy 243

Norway 33

dynamics of polymorphism 116

family studies 47,234 
variants 51, 248 Gene flow in Brazil 119

Gene frequency estimation, blood groups

345 Germany, South West, distribution of Gm

types 57 Gipsies (Swedish), blood group

distribution $134 \mathrm{Gm}$ types, distribution in South West

Germany 57 G-6-PD deficiency, family study 21 Haemoglobin S, B2 and beta thalassaemia

in same family 371 Haptoglobin types, distribution in

Castilla (Spain) 140

Swedish gipsies 134

Heart disease, congenital, and blood

groups 261 Hydrocephalus and blood groups 261 Inbreeding and congenital malformations

179 India, ear lobe attachment types 77 Italy, Northern, Gc types 243 Kell blood groups and disease 288 Lapps, Finnish, Gc types 45

- $\quad$ Tf types 63

- $\quad$ Norwegian, Gc types 126

Leukaemia and blood groups 261

Linkage relations, Norrie's disease and

Xg blood group system 103 -, beta and delta loci 371 Malformations in Northeastern Brazil 177

-, see also Heart disease, congenital, and

Hydrocephalus 3 -Methoxy-4-hydroxy-mandelic acid

excretion in twins $319 \mathrm{MN}$ blood groups and disease 277

in Swedish gipsies 134

Mortality in Sweden Supplementum Multiple sclerosis, family studies 165 Muscular dystrophy

(Duchenne) and limb

blood flow 337 Mutation in tissue culture 155

Index rerum

379

Nephritis, nephrosis and blood groups 261 Nome's disease and Xg blood groups, linkage relations 103 Norway, distribution of Gc types 33 Palmo-mental reflex, genetics 327 P blood groups and disease 291 Phosphatase, serum alkaline, in pregnant

women and newborns 218 Pseudocholinesterase, silent gene 201, 208 Race mixture, Brazil 119

Retest reliability 358 Rhesus-ABO interaction 224 - blood groups and disease 281

in Swedish gipsies 134

Rheumatic fever and blood groups 261 Secretor character and disease 297 Serum alkaline

phosphatase, see

Phosphatase

Sex chromatin in males, prevalence 256 Smallpox vaccination and anti-A titre 13 Spain

(Castilla), distribution of Hp types

140 Sweden, gipsies, blood group distribution

134

- $\quad$ mortality Supplementum

Tf types, Finland 63

- $\quad$ Lapps (Finnish) 63

Thalassaemia, beta, $\mathrm{Hb} \mathrm{S}$ and $\mathrm{Hb} \mathrm{B} 2$ in

same family 371 
- $\quad$ delta, and hereditary persistence of

foetal haemoglobin 190 Twins, excretion of mandelic acid 319 Vaccinia, see Smallpox Xg blood groups and Norrie's disease,

linkage relations 103 